\title{
Comfort Levels and Communication Styles of Sexual Health Educators: An Interdisciplinary Study
}

\author{
Kathleen A. Greenan \\ Ph.D., Assistant Professor \\ University of Indianapolis
}

Doi: 10.2478/ajis-2019-0011

\begin{abstract}
This study explored sexual health education (SHE) through the lens of public school educators in the United States of America. It examined their comfort levels and the barriers educators faced by asking, "How comfortable are educators when communicating sexual health topics to adolescents for them to build a foundation to become sexually healthy adults?" The qualitative, phenomenological study included 11 public school teachers among three school districts in the State of Indiana. Conducting intimate, faceto-face interviews with participants advanced and expanded interdisciplinary research. Educators shared their beliefs and values regarding SHE instruction and levels of sexuality comfort. Three findings emerged from the data that can contribute to research in the fields of education, public policy, public health, and communication: (1) An inclusive sexual health education program can provide educators with more sexuality comfort, (2) Teacher training and instructional materials relate to an educator's sexuality comfort level and willingness to communicate SHE, and (3) An educator's level of sexuality comfort may likely increase if engaged in SHE decision-making policies. At the time of the study, State policies prohibited comprehensive education, although participants preferred a more inclusive approach to teaching, SHE. Additionally, the concept of sexuality comfort (1984) was reconstructed and revised. This study offered an in-depth exploration into a topic - sexual health - that affects all individuals and established a foundation for future qualitative and quantitative studies.
\end{abstract}

Keywords: Communication, Sexual Health Education, Public Health, Sexuality Comfort, Public Policy

\section{Introduction}

A report by the Centers for Disease Control and Prevention ((CDC), 2019) showed less than half of high schools in the United States of America (USA) are achieving the CDC's goal of teaching 19 sexual health education (SHE) topics to adolescents. Teens and young adults account for $50 \%$ of new cases of sexually transmitted diseases (STDs) every year throughout the U.S.A. (CDC, 2016). Of the 50 states and Washington D.C., Indiana's figures were higher than national averages across most categories, thus, the reason it was the focus of this study (U.S. Dept. HHS, 2015). For example, $42 \%$ of high school students throughout Indiana are sexually active - an equal ratio of males to females. Additionally, Indiana ranked within the top half of teen births in 2015 at a rate of 30 out of 1,000; the national number of teen birth rates was 15 out of 1,000 (Indiana Department of Education, 2019). Statistics of risky teenage sexual behaviors and the rates of STDs have remained consistent over the years; 10 million new cases occur every year throughout the U.S.A. and, of these, teens and young adults account for 50\% (CDC, 2016). Table 1 provides 2015-16 health outcomes of the county in Indiana that was examined. 
Table 1. County, State, and National Trends, 2015-2016

\begin{tabular}{|l|c|c|c|}
\hline Health Factor & County & Indiana & National \\
\hline $\begin{array}{l}\text { Sexually Transmitted Disease } \\
\text { (per 100,000 population) }\end{array}$ & 616 & 438 & 479 \\
\hline $\begin{array}{l}\text { Teen Birth Rate } \\
\text { (per 1,000 female population ages 15-19) }\end{array}$ & 20 & 30 & 15 \\
\hline $\begin{array}{l}\text { HIV Prevalence Rate } \\
\text { (per 100,000 population ages 13+) }\end{array}$ & 94 & 196 & 49 \\
\hline
\end{tabular}

Source: Data provided by the Indiana Department of Education, 2018

The number of unplanned pregnancies and STDs is a significant problem; yet, another issue exists that few studies have examined: the comfort levels of educators who teach SHE to adolescents. If SHE is offered in Indiana public schools, educators must emphasize (1) abstention from sexual activity outside of heterosexual marriage, (2) abstention from sexual activity to be the only way to avoid out-of-wedlock pregnancy and STDs, and (3) establishing a mutually faithful monogamous relationship in the context of a heterosexual marriage (Indiana General Assembly, 2017). Educators were not required to discuss the negative outcomes of teen sex. In March 2018, the Indiana Senate approved a controversial bill that requires schools to send two permission slips to parents before providing instruction, as well lesson plans. Opponents of the new law preferred the opt-out option meaning the onus was on parents to remove their child from SHE (Kelly, 2018). To determine the comfort levels of SHE educators, the following research questions were posited:

1. How comfortable are educators when communicating sexual health topics to adolescents for them to build a foundation to become sexually healthy adults?

2. How do educators reportedly communicate SHE to students?

3. What approaches of communicating SHE do educators use to teach it?

4. What obstacles do educators face when implementing SHE?

5. How do educators' values and beliefs influence their instructional choices related to SHE topics?

The field of communication is vast and includes several styles, forms, and approaches. Check's (1985) definition of communication applies to education in the context of a classroom setting: "...a complicated transactional process that results in shared meaning between the teacher and the learner. It is a dynamic process of sending and receiving messages while competing against numerous distractions" (p. 76). Check defined distractions as "excessive noise level" or "movement from students" (1985, p. 76). In a study by Burleson and Samter (1990), students reported that teachers who were effective communicators were better teachers and enhanced their learning and motivation. Language educators used assisted in creating and shaping students' understanding of reality. Frymier and Houser (2000) reported the relationship between teacherstudent affects learning and cognition, and effective classroom communication is the primary approach in the development of the teacher-student relationship. Still, students have described sex education programs as outdated, unimpressionable, and detached from reality (Auteri, 2017).

Graham \& Smith's (1984) operational definition of "sexuality comfort" framed this study since it applied to sexual health education. It emphasizes the importance of teaching sex education to, and expressing respect and tolerance toward, students. The researchers conducted a qualitative study in 1984 that operationalized the concept. With $97.2 \%$ reliability from independent coders, they discovered that communication skills and sexuality comfort have a reciprocal and dependent relationship; thereby, the more comfortable a teacher was with a topic, the more effectively it would be conveyed to adolescents. The researchers suggested an educator's comfort level is central to teach SHE and defined sexuality comfort as:

- Feeling pride and security in one's own sexuality,

- being able to effectively communicate about sexual health to students while expressing respect and tolerance for their values,

- being sensitive to an individual's anxieties and encouraging them to explore sexual health 
issues and values on their own,

- realizing the importance of how the educator influences students,

- an educator's confidence in their skills and knowledge about sexual health to teach it

- using effective methods to teach SHE, and

- acknowledging the importance of SHE that provides individuals space for inquiry.

Two primary, formal SHE programs exist throughout the U.S.A.: abstinence-only and comprehensive education; they determine the dialogue in classrooms according to the Sexuality Information and Education Council of the United States (SIECUS, 2008). Policy makers, education leaders, and educators have defined abstinence as, "postponing sex or never having had vaginal sex or refraining from further sexual intercourse if sexually experienced... or not engaging in coitus." (Santelli et al., 2006, p. 73). It excludes teacher-student discussions of how and where to obtain methods of birth control and how to use them effectively. Alternatively, comprehensive education encourages individuals to explore sexual health and aligns with Graham and Smith's definition of sexuality comfort. In addition to addressing abstention from sexual intercourse as the most effective way of preventing unintended pregnancy and STDs, it explores options for methods of birth control and proper usage of condoms.

Sex education was not mandated by the State of Indiana during this study, or to date, and did not require schools to offer sex education to students. However, if SHE was offered, educators were required to emphasize (1) abstaining from sexual activity outside of heterosexual marriage, (2) abstaining from sexual activity to be the only way to avoid out-of-wedlock pregnancy and STDs, and (3) establishing a mutually faithful monogamous relationship in the context of a heterosexual marriage (Indiana General Assembly, 2017). Moreover, according to SIECUS (2015), Indiana law states:

\begin{abstract}
...the department of education must work with the department of health to develop AIDS prevention educational materials and make them available to school districts. These materials must "stress the moral aspects of abstinence from sexual activity" and "state that the best way to avoid AIDS is for young people to refrain from sexual activity until they are ready as adults to establish a faithful and monogamous marriage.
\end{abstract}

In March 2018, the Indiana Senate approved a controversial bill that would require schools to give parents two, formal notices before teaching SHE. Accordingly, parents would choose to opt their child into the program. Further, it requires educators to provide parents with lesson plans and instructional materials ahead of time. Shoemaker (1987) found that most parents wanted their child enrolled in comprehensive education that taught how to obtain methods of birth control and use them effectively. Approximately $90 \%$ of parents supported having SHE offered in public schools (Santelli et al., 2006). In a 2011 survey by Planned Parenthood Federation of America, 82\% of parents had discussed matters of sexuality with their children; however, $43 \%$ of them were uncomfortable talking to their child about abstinence and birth control and reported feeling unprepared and inadequate to teach sexuality to their child (Auteri, 2017). "...Opponents of the new law prefer the opt-out process that some schools are currently using, meaning if there is no response from a parent, the child remained in class" (Kelly, 2018, para.9).

This study gained a deeper understanding of the barriers that public-school educators faced when teaching SHE such as how to address issues and construct messages. Furthermore, teacher training/s and professional development for SHE was not promoted, prioritized, or provided to educators. In a survey by Hoff and Greene (2000), 65\% of teachers lacked freedom in constructing SHE messages and directing conversations, which negatively affected their level of confidence in their skills and knowledge. Next, educators reported school or district policies as a major barrier. Forty-five percent of teachers were concerned about unexpected responses or reactions from parents, students, and administrators about their teachings and evaded conflict by avoiding conversations about sensitive health information with students (McCroskey \& Richmond, 2013).

\title{
2. Research Methods
}

A phenomenological, qualitative design guided the research "to go beyond the shorthand...explanations available from surveys" (Stone, 2007, p. 15). Conducting semi-structured, 
in-depth interviews provided access to first-hand interactions while an interpretive framework guided the study due to the instrument; the framework underscored the human experience by gaining educators' values, opinions, and beliefs about teaching SHE (Stake, 2010). Accordingly, each participant brought his or her life experiences and worldview to the interview. The research design provided "....access to the most complicated social and educational issues...based on the concrete experiences of people (Seidman, 2013, p. 7)."

\section{Participant Selection}

Indiana statistics tracked higher than most states and national benchmarks and was, therefore, the focus of the study. Data collection consisted of a non-random sample population to identify specialized sources of relevant information about the topic. Participants included 11 public school educators. The ratio of women to men participants - seven to four - was determined by the number of educators who were qualified to teach SHE and agreed to participate in the study. Participants were from three public high schools and one junior high school among three school districts in a mid-sized city in Indiana. All schools resided within proximity to one another within the same county. According to student profiles of each school, most students were White followed by an increasing Hispanic population. Schools varied across socio-economic, academic, and demographic statuses of teachers, families, and students. The criteria of variation included educators who ranged in experience from one year to educators nearing retirement. A second criterion of variation included teachers in the Departments of Health and Physical Education (PE) and Family and Consumer Sciences (FACS). Table 2 illustrates each school's profile, and Figure 1 compares student profiles.

Table 2: School Profiles, 2016-2018

\begin{tabular}{|c|c|c|c|c|}
\hline School & Number of SHE Educators & Student Population & Rating & SHE Offered \\
\hline $\mathbf{1}$ & 3 & 1,983 & $\mathrm{C}$ & Yes \\
\hline $\mathbf{2}$ & 3 & 1,983 & $\mathrm{~B}$ & Yes \\
\hline $\mathbf{3}$ & 2 & 1,777 & $\mathrm{~A}$ & Yes \\
\hline $\mathbf{4}$ & 3 & 1,129 & $\mathrm{~A}$ & Yes \\
\hline
\end{tabular}

Source: Data provided by the Indiana Department of Education, 2018

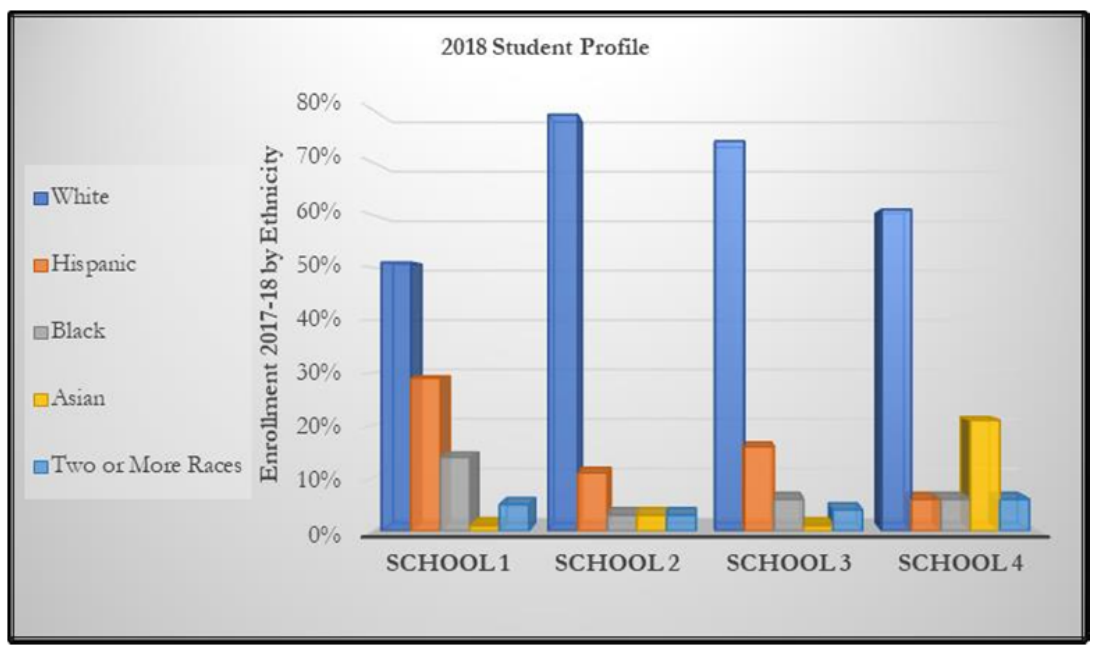

Figure 1. Student Profile, 2017-2018. Reprinted from Search School and Corporation Reports, In Indiana Department of Education., Retrieved on March 14, 2018 from https://www.doe.in.gov/. 


\section{Instrumentation}

Prior to data collection, a pilot study was conducted to evaluate the research instrument, a protocol of questions. As a result, the final instrument was edited. Participant interviews were semistructured and one-on-one, and applying an interpretive methodology permitted participants to explain their personal experiences and the researcher to decode, analyze, clarify, and understand participants' lived experiences. Consistency was central during data collection and analysis to ensure credibility of the research. The same protocol of questions was used for each moderatelystructured interview and included open-ended questions and probes that provided comprehensive impressions, ideas, questions, and observations of the data.

\section{Data Analysis}

Given the variety and amount of data that were collected, analysis consisted of simultaneous coding methods to categorize the data: attribute, in vivo, provisional, and open coding. The first cycle, attribute coding (Table 3), provided foundational and demographic information of participants (e.g. years of teaching experience), revealing similarities and differences among participants and school districts. Next, in vivo coding used participant quotes, anecdotes, and information to organize patterns, subthemes, and themes. The third method, open coding, advanced exploratory analysis by offering a general idea and broad understanding of emerging themes. Finally, provisional coding is a predetermined "...set of codes prior to fieldwork" (Saldana, 2009, p. 120). Two sets of predetermined codes were applied to the data that used a deductive approach: Graham \& Smith's definition of sexuality comfort and the CDC's sexual health recommendations. To maintain dependability across data, participant transcripts were re-analyzed. Additionally, crosschecking increased the reliability of data analysis; participants were requested to read his or her transcript and offer corrections, clarifications, additions, and/or edits of the data. Crosschecking increased the reliability of the data and the trustworthiness of the analytical process.

Table 3. Attribute Coding of SHE Educators

\begin{tabular}{|l|c|l|c|l|l|l|l|}
\hline $\begin{array}{l}\text { Educator } \\
\text { Name }\end{array}$ & $\begin{array}{l}\text { School } \\
\text { District }\end{array}$ & $\begin{array}{l}\text { Educator } \\
\text { Title }\end{array}$ & $\begin{array}{l}\text { Years } \\
\text { Teaching } \\
\text { SHE }\end{array}$ & $\begin{array}{l}\text { Licensed } \\
\text { Health } \\
\text { Educator }\end{array}$ & Sex & Race & $\begin{array}{c}\text { Offered } \\
\text { Training }\end{array}$ \\
\hline \hline Tom & 2 & Health/PE Educator & 7 & Yes & M & White & No \\
\hline Chrissy & 4 & FACS Educator & 6 & $\begin{array}{l}\text { License in } \\
\text { process }\end{array}$ & F & White & No \\
\hline Clarke & 3 & Health/PE Educator & 11 & Yes & M & White & No \\
\hline Joni & 4 & Health/PE Educator & 39 & Yes & F & White & No \\
\hline Kara & 3 & FACS Educator & 14 & Qualifies & F & White & $\begin{array}{c}2012 \text { SHE } \\
\text { Conference }\end{array}$ \\
\hline Landon & 1 & $\begin{array}{l}\text { Health \& Wellness } \\
\text { Educator }\end{array}$ & 1 & Yes & M & White & No \\
\hline Lena & 2 & FACS Educator & 8 & No & F & White & No \\
\hline Matthew & 4 & Health/PE Educator & 39 & Yes & M & Black & No \\
\hline Rita & 3 & $\begin{array}{l}\text { FACS Educator; } \\
\text { Department Head }\end{array}$ & 27 & Qualifies & F & White & No \\
\hline Sherry & 1 & FACS Educator & 8 & $\begin{array}{l}\text { License in } \\
\text { process }\end{array}$ & F & White & No \\
\hline Skye & 1 & FACS Educator & 30 & Yes & F & White & No \\
\hline
\end{tabular}

\section{Thematic Analysis}

Thematic analysis (TA) transformed codes into themes and linked categories to subcategories to examine the data. The process involved generating preliminary codes and discerning patterns across the data set; categorizing relevant themes; creating and analyzing a thematic map; identifying, defining, and refining themes; and reporting the findings. Upon data analysis, it was evident that sexuality comfort served as the core concept of the study. Table 4 displays a thematic 
map, step four of TA, from data analysis that distinguished 10 codes and included four themes: (a) comfort level (b) communicating SHE (c) teaching strategies, and (4) obstacles teachers face.

Table 4: Thematic Map: Sexuality Comfort as Core Concept, Themes, Sub Themes

\begin{tabular}{|l|l|l|l|}
\hline Sexuality Comfort & $\begin{array}{l}\text { Theme 2 } \\
\text { Communicating SHE }\end{array}$ & $\begin{array}{l}\text { Theme 3 } \\
\text { Teaching Strategies }\end{array}$ & $\begin{array}{l}\text { Theme 4 } \\
\text { Obstacles Teacher Face }\end{array}$ \\
\hline $\begin{array}{l}\text { Theme 1 } \\
\text { Comfort Level }\end{array}$ & $\begin{array}{l}\text { 2a. Interjecting beliefs, values, or } \\
\text { opinions } \\
\text { 2b. R-e-s-p-e-c-t }\end{array}$ & $\begin{array}{l}\text { 3a. SHE topics } \\
\text { information } \\
\text { 3b. Feeling comfortabluation levels of } \\
\text { teaching methods } \\
\text { 1b. Feeling } \\
\text { uncomfortable } \\
\text { 2c. Responding to student } \\
\text { questions }\end{array}$ & 4c. Teaching gray areas \\
\hline
\end{tabular}

\section{Findings}

Data analysis led to three key findings. First, an inclusive sexual health education can provide educators with more sexuality comfort. Second, lacking teacher training and instructional materials affect an educator's willingness to communicate and level of sexuality comfort. Third, an educator's level of sexuality comfort will likely increase if he or she is engaged in policy-making decisions. Figure 2 displays sexual health topics that participants felt comfortable teaching. Figure 3 shows sexual health topics that participants excluded from instruction to adhere to state policies but would feel comfortable teaching if they were trained.



Figure 2. Current and Comfortable Teaching Topics 


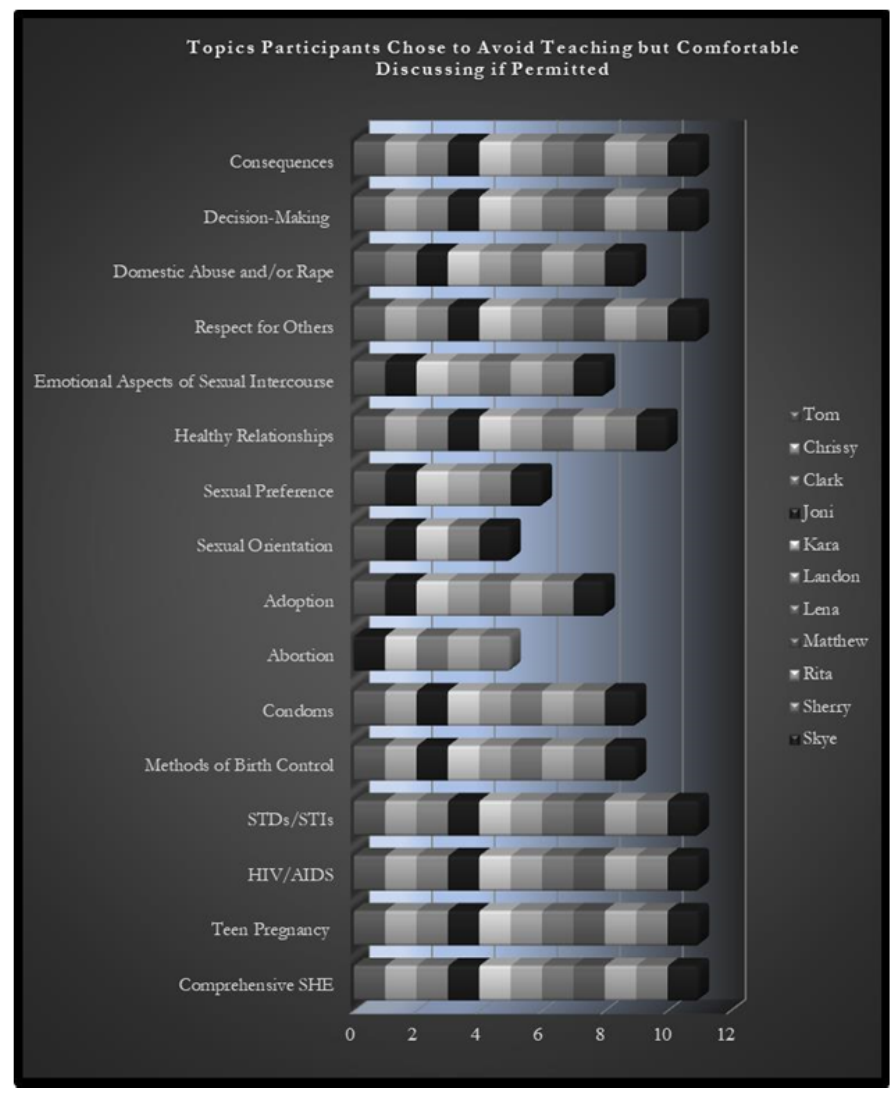

Figure 3. Topics Participants Excluded but Would Teach if Provided Training

\subsection{Finding 1: An inclusive sexual health education can provide educators with more sexuality comfort.}

Upon in-depth data analysis, providing an inclusive education to students is an essential first step to increasing an educator's sexuality comfort. A central characteristic of effective communication is inclusion, which means to be comprehensive and broad in scope. When applied to SHE, inclusion may permit educators to teach material to all populations of students including those who are sexually abstinent or active and hetero- or homosexual. Indiana programs and policies currently exclude specific student populations. According to the Guttmacher Institute (2017), youth between ages 13-18 reported using the Internet to learn about sex - 19\% heterosexual, $40 \%$ questioning, $65 \%$ bisexual, $78 \%$ lesbian/gay/queer. An increased percentage of adolescents who identified as lesbian, gay, bisexual, transgender, or questioning sought alternative sources to educate themselves.

Every participant stated that current SHE policies prevented or discouraged classroom discussions about gender identity, orientation, sexual preference, and abortion, which led to an exclusion and isolation of students. Participants were uncomfortable when addressing students' inquiries about abortion, sexual preference, date rape, contraception, oral sex, and/or gender orientation; furthermore, they were dissatisfied with current SHE policies. Educators teetered between state standards and providing accurate information to students. One participant believed that offering comprehensive education was more practical for adolescents: 
You're talking to 1,700 students in the building. There's going to be kids who are not...abstinent...those big chunks of kids. What can we do to help them? I'd much rather educate them on how to use a condom than to have a baby or an STD. I just think they should be knowledgeable, so comprehensive I think is the better way...they're high schoolers. They're curious...they get it from their friends...I think if they get it from a trusted person, it's in their benefit. - Lena

Overall, participants reported feeling apprehensive about addressing controversial topics due to negative reactions or consequences they may receive from parents, students, or administrators. Hence, many of them hosted guest speakers to address topics such as safe sex. Moreover, findings revealed teachers typically managed formal, classroom conversations by using avoidance, deflection, and/or humor.

Abortion...I just tell them, "Honey, you would probably want to Google that. And that way I don't address it." - Rita

I have had some kids ask about gay relationships and I say, "Girls, first of all, if you go to a movie with a guy who is gay, you don't have to worry about date rape...the biggest blow to your ego is going to be if some guy tries to pick up your date." And they're like, "Oh!" And so, they think it's funny. - Joni

Next, educators believed they lacked control when developing SHE instruction. For example, Landon was required to receive approval of the final exam from school administrators and believed students lacked key takeaways about sexual health.

Even in the first semester, I asked about changing some of [the curriculum], and it just didn't seem like I was getting anywhere. I don't want to say that I teach toward the final, but I have to make sure that I cover the things that are going to be on there...I don't talk about birth control or condoms [or] abortion 'cause of State standards...I don't know how much trouble I could get into...l'd rather talk about that stuff. I think it's more important, more realistic. - Landon

7.2 Finding 2: Teacher training and instructional materials affect an educator's willingness to communicate and their level of sexuality comfort.

School districts and leaders are responsible for distributing accurate, timely instructional material to educators. Participants stated that training opportunities were not accessible, encouraged, or provided by school districts or the state and expressed concern about lacking accurate information, which decreased their confidence in their knowledge and skills, as well as comfort levels. Tom has taught SHE for seven years without training:

Kids would ask me:

Students: What would you think if I went [in the boys/girls' restroom]?

Teacher: Shut up, shut up. What, are you going to go in the girls' restroom?

Students: I could if I wanted to.

Teacher: Yeah, I guess you could, couldn't you.

I just try to make light of it and move on 'cause I really didn't have anything wise to impart to them. I don't know what would be appropriate. I don't have any training in it, you know, what's appropriate to talk about, what's not. - Tom

Lena shared a similar experience:

We don't talk about [rape]...I don't bring it up. I don't know the research behind it, and I don't want to speak ill of something I don't know about...it is hard because kids will have this misconception on what it is, and I say, "Well, maybe you should do your research." I can't explain it to them. - Lena

Matthew was neither confident nor comfortable addressing the topic of emotions and elected to exclude it: 
There is an emotional aspect of teaching sex ed, and I am not equipped to teach this. Fortunately, this aspect does not arise during lessons. - Matthew

The data revealed the importance of recognizing and understanding SHE terminology that is age-appropriate and relatable to students. This supports literature that reported the need for teachers and students to converse in a relatable way. Lena's biggest challenge was pairing abstract language with corresponding visualizations:

Terminology is most difficult just because it's all new information....and having to teach abstract things like talking about sex...It's so abstract that they have to see a visualization, and I can't always provide a visualization. - Lena

A lack of district or State-supported training opportunities prevented educators from teaching recent facts and statistics that affected adolescents. Kara was uncomfortable discussing gender orientation and identity and believed that crafting communication messages was the most challenging aspect of SHE. Kara described a female student who identified as a boy:

I heard teachers say, "Hey do you have so-and-so in class? That student likes to be called Skyler because it's unisex." So, do you say him? Do you say her? I think what you don't know is scary...I think that's human. I have one. I'm very close to her. She's a junior and she is a lesbian...she identifies more as a male than a female. I mean she uses our male restrooms...I'll be very honest, she's heavier set...her breasts don't appear as noticeable. They kind of blend with the rest of her body. She wears hats. I thought she was a boy when I first had her on my roster three years ago. Kara

This data revealed a lack of understanding of terminology and language. When Kara stated, "I have one," she was referring to Skyler, a female student who identified as a boy. "One" is a genderneutral pronoun that describes an unspecified person. Kara had placed Skyler in an "Other" category since she lacked communication training. This example underscored the importance of arming educators with professional development opportunities and trainings. Increasing educators' awareness about current sexual health issues can provide them with accurate data and assist with a better understanding of these issues. Tom also acknowledged discomfort with a transgender student.

I had a girl who was going by "Nick"...she changed what she wanted to be referred to even in the pronouns that were used... When I had her as a sophomore, I had notes from counselors that said she wanted to be known as a "he" and use "he pronouns" and it's like, "Are you kidding me?" I try to be respectful, and I would never let somebody say something derogatory in class, but it was awkward, and I sure wasn't very comfortable with it...I don't know what would be appropriate. I don't have any training in it, you know, what's appropriate to talk about, what's not. - Tom

Finally, Clark felt unqualified to answer questions about gender identity and sexual orientation.

Now we have had students in PE, so it's getting more prevalent. Last semester I had a student who basically came out after class...The conversation was on the verge of transgender issues, some gender questioning type thing, "What do I do?" I tried to encourage her to go see her guidance counselor. - Clark

7.3 Finding 3: An educator's level of sexuality comfort may likely increase if he or she is engaged in SHE decision-making policies.

Participant-educators desired more assistance and support from state and school officials to provide effective and meaningful instruction to students. It was not uncommon for participants to engage in interpersonal conversations with students. The data revealed that students approached teachers outside of class to disclose private information or ask personal and sensitive questions. Participants were more comfortable communicating with students about sex, sexual preference, teen pregnancy, STDs, contraception, and emotions one-on-one. Moreover, teachers believed 
current policies and resources were not representative of students' general beliefs and values:

Kids today compared to when I was young are way more accepting...They don't even understand when [I] talk about race in the 60s or gay hatred; they just look at me sometimes like, "What are you even talking about?" We have same-sex couples here and people just think it's normal. - Sherry

\section{Landon desired a curriculum that provided a broader scope of sex education:}

It should be a different version....addressing consequences, condoms, teen pregnancy. I would definitely put consequences above everything...it's really concerning. I think that whatever we're doing now is not working, so we need to try something a little different...it's got to be taught a lot lower than [high school]...there's two $7^{\text {th }}$ graders that are pregnant over at the middle school. Landon

\section{Lena echoed Landon's statement regarding consequences:}

We leave out emergency contraception...so on the diagram picture, it has Emergency $B$ on there, and I just tell [students] to mark it out. We're not going to talk about. I think the whole Plan B emergency contraceptive is important...kids don't understand what it fully is or the negative effects that it could have on the body...they see it as a pill, so they confuse it with birth control pills...they don't know the procedure. - Lena

According to Kara, programs did not accurately present the sobering reality about HIV and AIDS:

If they have learned about [HIV and AIDS], they have learned about it from the Children's Museum from the Ryan White exhibit...a lot of them go in elementary school...he's very sick, he died, sad life, people weren't nice...nothing sexual...They jumped to four years later and they're watching Straight Outta Compton...seeing what Easy $E$ is doing - having parties, there's a lot of sexual interaction going on, and they make it look fun...they don't show any of the consequences. - Kara

In addition to lacking current information, most participants did not use state-approved textbooks and pointed to outdated, inaccurate information. Textbooks ranged between 8-12 years old.

It's pretty generic...we don't get real, real specific, but that's, I think, probably where public education does a disservice probably because in order to really cover the topic, you have to get pretty specific. - Clark

My text is very weak...it does cover the state standard. I just give more detail...things come out new. New and improved type[s] of things...It's just keeping up on my knowledge. - Rita

Participants echoed one another by using alternative resources they found or created such as diagrams, activities, and worksheets. Kara's instructional materials included a video:

I do a video...This one lady...says some really weird things like for a male, "The penis is their best friend." Some of it is so stupid, but the thing is, it's really hard to find something that's conservative enough that meets standards, but yet explains to them the different types of contraceptive options...sometimes I have a really hard time...Like I said, training is mostly self-advocated. - Kara

\section{Conclusions}

The data concluded that every participant preferred taking a broader, more practical approach to teaching students about sex, which Indiana's policies did not prohibit. Students who were pregnant, sexually active, gay, transgender, and/or contracted an STD or infection were, by law, excluded from classroom conversations. Moreover, teachers were not required to provide information that was medically accurate, unbiased, and age or culturally appropriate. Every participant emphasized the importance of creating a comfortable learning environment where sensitive topics such sexual 
preference could be communicated.

Research revealed most educators provided more than two minutes of classroom-based discussions, which refuted literature by Lawrence et al., (2015). All participants agreed that teaching sex only within the context of marriage was unrealistic, impractical, and countered the actions of students who were curious about oral sex, pregnancy, the emotional aspects of sex, sexual preference, and gender identity or orientation. Although participants stressed the benefits of abstinence either briefly or throughout the unit, they were generally uncomfortable teaching abstinence-only education and unanimously agreed offering comprehensive education would accurately reflect the reality of society. Finally, each participant desired information about methods of contraception, the negative outcomes of teen sex, managing a budget, and avoiding coercion. To paraphrase one participant, too many kids are not taught this at home, and they grow up without having the knowledge they need.

The study was limited to 11 SHE educators in one community, and the results have limited generalizability. Still, using a small sample size was valuable since SHE has never consisted of a one-size fits-all program; the success of a program can vary based on states and school districts. Additionally, curriculum and instructional materials were inconsistent among every school and participant. FACS courses had different curricula than health courses. Despite these limitations, research findings provided information and an understanding that can be replicated in larger, future studies.

The American culture has changed immensely since the conceptualization of sexuality comfort. However, the definition is as meaningful and applicable to research today. Conversations about gender orientation, identity, and sexual preference have become commonplace in mainstream society. This study revived and evolved the 1984 definition of sexuality comfort that consisted of seven parts with multi-part meanings listed below (multi-part meanings are underlined).

Graham \& Smith's original definition of sexuality comfort (1984)

1. Feeling pride and security in one's own sexuality

2. Being able to effectively communicate about sexual health to students while expressing respect and tolerance for their values

3. Being sensitive to an individual's anxieties and encouraging them to explore sexual health issues and values on their own

4. Realizing the importance of how the educator influences students

5. An educator's confidence in their skills and knowledge about sexual health to teach it

6. Using effective methods to teach SHE

7. Acknowledging the importance of SHE that provides individuals space for inquiry

'Feeling pride and security in one's own sexuality,' are two different concepts: "pride" and "security" have different meanings. Synonyms of 'pride' include satisfaction, delight, and dignity. In contrast, 'security' means safety, confidence, and well-being. Data could not be applied to compound meanings and codes. To resolve this, I disassembled and revised the 1984 definition of sexuality comfort to reflect singular meanings. Revisions are underlined.

Revised definition of sexuality comfort (Greenan, 2018)

1. Feeling pride in one's sexuality

2. Feeling security in one's sexuality

3. Being able to effectively communicate about sexual health to individuals

4. Expressing respect and tolerance for individuals' values

5. Being sensitive to individuals' anxieties

6. Encouraging individuals to explore sexual health issues and values on their own

7. Realizing the importance of how the educator influences individuals

8. An educator's confidence in their knowledge about sexual health to teach SHE

9. An educator's confidence in their skills about sexual health to teach SHE

10. Using effective methods to teach SHE

11. Acknowledging the importance of SHE that provides individuals space for inquiry

Amending and applying a broader, more inclusive definition of sexuality comfort can advance future studies by conducting a statewide study to extend this research. A revised protocol of questions can be applied to future research. For a quantitative study, open-ended questions could 
be revised to closed-ended questions that have similar meanings in which participants respond to a survey.

\section{Recommendations}

According to Indiana law, the state departments of education and health are responsible for developing and disseminating educational materials to school districts. First, state and district leaders can collaborate with county health departments and educators to replace outdated textbooks by creating and disseminating instructional packets to educators and adolescents equipped with current facts, statistics, and age-appropriate terminology. Instructional packets could include teaching methods, activities, diagrams, photos, questions and answers, and small group discussion topics that mirror societal norms. Participants stated the importance of having honest and transparent conversations with students about practical issues such as respect, consent, date rape, abusive relationships, managing a budget, and sexual harassment. Instructional packets may provide examples of presentations or demonstrations about these issues that occur in schools, workplaces, and on college campuses. It is essential for students to detect and identify them upon high school graduation. A portion of the packet may address communication as a basic need and activity engaged in by humans.

Next, the state or school districts could compile and disseminate an internal document to teachers to address student questions about STDs, teen pregnancies, gender identity and orientation, and sexual preference. Although state policies prohibit these teaching topics, teachers still receive questions from students, both interpersonally and in groups. Providing recent facts and statistics may support and prepare teachers to respond to sensitive questions. Although eliminating discomfort is unlikely, offering teacher training about the principles of communication, audience analysis, composing meaningful and coherent messages, developing effective arguments, asking curious questions, embracing uncertainty, and improving skills to strengthen confidence can provide opportunities to teachers that may increase their comfort levels.

Finally, the 2018 policy requires parents to opt their child in to SHE. This new law can be used as an opportunity for school administrators and educators to open the line of communication with parents to establish and foster trust. In addition to sending permission slips to parents, schools can emphasize the value and importance of SHE topics such as terminology, consent, and respect. SHE is a lifelong lesson, and public schools have an unparalleled opportunity to include, inspire, and influence student populations. Although state policies determine SHE curriculum and instruction, educators are central participants in SHE discussions and often serve as liaisons between schools and parents but are often left out of policy-making discussions. Public schools provide a primary resource for the development of student identities, and state, district, and school leaders can invite and encourage educators to join these critical conversations.

\section{References}

American Adolescents' Sources of Sexual Health Information. (2017). Adolescents' reports of formal Sexual Health Education. Retrieved from Guttmacher Institute website https://www.guttmacher.org/factsheet/facts-american-teens-sources-information-about-sex.

Auteri, S. (2017, February 19). The way we teach sex-ed is old and ineffective. Here's how to fix it. Pacific Standard. Retrieved from The Week website http://theweek.com/articles/678865/way-teach-sexed-oldineffective-heres-how-fix.

Burleson, B.R., \& Samter, W. (1990). Effects of cognitive complexity on the perceived importance of communication skills in friends. Communication Research, 17(2), 65-182.

Centers for Disease Control and Prevention. (March 27, 2019). Sexual risk behavior: HIV, STD, and teen pregnancy prevention. Retrieved from http://www.cdc.gov/HealthyYouth/sexualbehaviors/.

Centers for Disease Control and Prevention. (2017, October 16). National center for HIV/AIDS, viral hepatitis, STD, and TB prevention. Retrieved from https://www.cdc.gov/nchhstp/stateprofiles/default.htm.

Centers for Disease Control and Prevention. (2015). New findings from CDC survey suggest too few schools teach prevention of HIV, STDs, pregnancy. Retrieved from http://www.cdc.gov/healthyyouth/data/profiles/results.htm.

Check, J. (1985). Communication skills in the classroom. Physical Educator, 42(2), 76. 
Frymier, A.B., \& Houser, M.L. (2000). The teacher-student relationship as an interpersonal relationship. Communication Education, 49(3), 207-219.

Graham, C.A., \& Smith, M.M. (1984). Operationalizing the concept of sexuality comfort: Applications for sexuality educators. Journal of School Health, 54(11), 439-442.

Greenan K.A. (2018). Revised definition of sexuality comfort.

Hoff, T., \& Greene, L. (2000). Sex education in America. A series of national surveys of students, parents, teachers, and principals. A view from inside the nation's classrooms. Retrieved from Kaiser Family Foundation website https://kaiserfamilyfoundation.files.wordpress.com/2000/09/3048-sex-education-inamerica-a-view-from-inside-the-nations-classrooms.pdf.

Indiana Department of Education (2019). Search school and corporation reports. Retrieved from IDOE website https://www.doe.in.gov/.

Indiana General Assembly 2018 Session. (2018). Senate Bill 65. Retrieved from Indiana General Assembly website http://iga.in.gov/legislative/2018/bills/senate/65.

Indiana General Assembly 2014 Session. (2017). Title 20. Ė̃ucation. Retrieved from Indiana General Assembly website https://iga.in.gov/legislative/laws/2017/ic/titles/020.

Kelly, N. (2018, January 31). Senate okays requiring sex education consent. The Journal Gazette. Retrieved from http://www.journalgazette.net/news/local/indiana/20180131/senate-oks-requiring-sex-education-consent.

Lawrence, J.F., Crosson, A.C., Paré-Blagoev, J.E., \& Snow, C.E. (2015). Word generation randomize trial: Discussion mediates the impact of program treatment on academic word learning. American Educational Research Journal, 52(4), 750-786.

McCroskey, J.C., \& Richmond, V.P. (2013). Willingness to communicate (WTC). Measurement Instrument Database for the Social Reience. rom http://www.midss.org/sites/default/files/willingness_to_communicate.pdf.

McCroskey, J.C. (1992). Reliability and validity of the willingness to communicate scale. Communication Quarterly, 40(1), 16-25.

McCroskey, J.C., \& Richmond, V.P. (1987). Willingness to communicate. In J.C. McCroskey \& J.A. Daly (Eds.), Personality and Interpersonal Communication (pp 119-131). Newbury Park, CA: Sage.

Office of Adolescent Health. (2015). Indiana adolescent reproductive health facts. Retrieved from U.S. Department of Health \& Human Services website https://www.hhs.gov/ash/oah/facts-and-stats/nationaland-state-data-sheets/adolescent-reproductive-health/indiana/index.html.

Planned Parenthood Federation of America. (2011, October 3; updated 2016). New poll: Parents are talking with their kids about sex but often not tackling harder issues. Retrieved from http://www.plannedparenthood.org/about-us/newsroom/press-releases/new-poll-parents-talking-their-kidsabout-sex-often-not-tackling-harder-issues.

Saldana, J. (2009). The Coding Manual for Qualitative Researchers. London, UK: Sage Publications Ltd.

Santelli, J., Ott, M., Lyon, M., Rogers, J., Summers, D., \& Schleifer, R. (2006). Abstinence and abstinence-only education: A review of U.S. policies and programs. Journal of Adolescent Health, 38(1), 72-81.

Seidman, I. (2013). Interviewing as qualitative research: $A$ guide for researchers in education and the social sciences $\left(4^{\text {th }}\right.$ ed.). New York, NY: Teachers College Press.

Sexuality Information and Education Council of the United States (SIECUS). (2015). State profiles: Fiscal year 2015. Indiana. Retrieved from SIECUS website http://siecus.org/document /docWindow.cfm?fuseaction=document.viewDocument\&ID=AD94E5B9F0DE0B664F2DFC59DC94E9B48 8976995AD3CC0C6D329D0B0ADB5CF1402ACE5878D9DAC3AD3FB3CBB71BF2A42.

Sexuality Information and Education Council of the United States (SIECUS). (2008). Sexuality education $Q$ \& $A$. Retrieved from SIECUS website http://siecus.org/index.cfm?fuseaction=page.viewpage\&pageid $=521 \&$ grandparentID.

Shoemaker, D. (1987). Sex education: The dissemination of family planning services and contraceptives in public school. Journal of Legal Medicine, 8(4), 587-611.

Stake, R.E. (2010). Qualitative research: Studying how things work. New York, NY: Guilford Press.

State Laws and Policies. (2016). Sex and HIV education. Retrieved from Guttmacher Institute website https://www.guttmacher.org/state-policy/explore/sex-and-hiv-education.

Stone, P. (2007). Opting out?: Why women really quit careers and head home. Berkeley and Los Angeles, CA: University of California Press. 